\title{
Analisis Teknis dan Ekonomis Pembangunan Kapal Ikan Menggunakan Laminasi Hybrid Antara Bambu Ori dengan Kayu Sonokembang dengan Variasi Arah Serat
}

\author{
Rizqi Dian Permana dan Heri Supomo \\ Departemen Teknik Perkapalan, Fakultas Teknologi Kelautan, Institut Teknologi Sepuluh Nopember (ITS) \\ e-mail: hsupomo@na.its.ac.id
}

\begin{abstract}
Abstrak - Kelangkaan Kayu Jati sebagai bahan utama pembuatan kapal ikan tradisional menyebabkan harga kapal semakin mahal. Alternatif kayu yang dapat digunakan sebagai material kapal adalah Kayu Sonokembang (Pterocarpus Indicus). Kayu Sonokembang merupakan kayu yang mudah untuk dikembangbiakkan, tergolong dalam Kelas Kuat dan Kelas Awet III, tetapi tidak tercantum dalam daftar kayu untuk konstruksi kapal kayu yang diterbitkan oleh BKI, berdasarkan literatur hasil penelitian didapatkan kuat tarik dan kuat tekuk laminasi Bambu Ori sebesar 160 MPa dan 84 MPa. Melihat potensi dari Kayu Sonokembang dan kekuatan dari Laminasi Bambu Ori, maka akan dilakukan laminasi hybrid terhadap kedua material tersebut. Pengujian tarik dan tekuk akan diaplikasikan pada laminasi hybrid sesuai standard ASTM D3500 (uji tarik) dan ASTM D3043 (uji tekuk) untuk mendapatkan nilai kuat tarik dan kuat tekuk, selanjutnya akan dilakukan perhitungan ukuran konstruksi sesuai dengan BKI 2013 Vol VII dan nilai ekonomisnya dibandingkan dengan penggunaan Kayu Jati KK II. Dari hasil pengujian diketahui hanya spesimen laminasi hybrid dengan variasi susunan serat sejajar yang memenuhi standard minimum dari BKI yaitu dengan nilai kuat tarik 114,636 MPa dan nilai kuat tekuk 111,606 MPa. Ukuran volumetrik konstruksi kapal ikan yang didapatkan adalah $10,27 \mathrm{~m}^{3}$ (laminasi hybrid) dan $13,75 \mathrm{~m}^{3}$ (Kayu Jati Solid), dan nilai ekonomisnya adalah Rp. 460.881.589,untuk laminasi hybrid dan Rp. 776.676.472,- untuk Kayu Jati Solid.
\end{abstract}

Kata Kunci-Laminasi hybrid, Bambu Ori, Kayu Sonokembang, volumetrik

\section{PENDAHULUAN}

$\mathrm{K}$ AYU Jati adalah bahan utama dalam pembuatan kapal ikan tradisional di Indonesia, kelangkaan Kayu Jati yang diakibatkan oleh penebangan liar yang tidak terkendali, kerusakan hutan di Indonesia pada periode 2009-2013 mencapai lebih dari 1,13 juta hektar per tahun [1]. Di sisi lain untuk memperoleh kayu yang memenuhi standar konstruksi dibutuhkan waktu yang cukup lama, yaitu sekitar 30-40 tahun.

Kelangkaan ini mengakibatkan harga Kayu Jati semakin mahal. Kemudian dipilih material Kayu Sonokembang sebagai material pengganti Kayu Jati sebagai bahan baku pembuatan kapal ikan. Kayu Sonokembang merupakan kayu yang memiliki pertumbuhan yang cukup cepat dan mudah berkembang biak yaitu dengan biji atau stek batang. Di
Indonesia kayu ini tersebar di beberapa daerah seperti Sumatera, Jawa, Sulawesi, Maluku dan Sumba. Dari segi ekonomis kayu ini memiliki harga yang lebih murah yaitu antara Rp. 250.000,- sampai dengan Rp. 3.000.000,- per $\mathrm{m}^{3}$. Kayu Sonokembang dimanfaatkan sebagai perabotan rumah tangga. Kulitnya sering digunakan sebagai pewarna pakaian. Meskipun kayu ini termasuk dalam kayu dengan Kelas Kuat III dan Kelas Awet III [2] namun penggunaannya sebagai bahan konstruksi jarang ditemukan, terlebih lagi dalam penggunaanya sebagai bahan konstruksi pembuatan kapal. Berdasarkan peraturan dari BKI, persyaratan kayu yang boleh digunakan dalam pembangunan kapal ikan adalah kayu yang memiliki Kelas Kuat III dan Kelas Awet III [3], namun kayu jenis ini tidak tercantum dalam tabel daftar kayu yang boleh digunakan sebagai material konstruksi kapal ikan.

Bambu Ori (Bambusa arundinaceae) adalah bambu yang pada buku batang dan rantingnya tumbuh duri. Ciri-ciri fisik dari bambu ini adalah berwarna hijau dengan panjang 15-25 m. Bambu jenis ini biasa tumbuh di sepanjang tepi sungai dan lereng bukit [4]. Dari penelitian yang telah dilakukan sebelumnya laminasi bambu ori memiliki kekuatan mekanis yang lebih tinggi dari pada kayu jati solid, yaitu dengan nilai tensile strength $160 \mathrm{MPa}$ dan bending strength $84 \mathrm{MPa}$ [5].

\section{URAIAN PENELITIAN}

Pada penelitian ini digunakan metode eksperimen statistik. Metode eksperimen adalah suatu penelitian yang dilakukan untuk mengetahui suatu akibat yang ditimbulkan dari suatu perlakuan yang diberikan secara sengaja yaitu akan dilakukan sebuah penelitian terhadap laminasi hybrid Bambu Ori dengan Kayu Sonokembang dengan variasi arah serat. Sedangkan metode statistik digunakan setelah dilakukan pengujian laboratorium berupa uji tarik dan uji tekuk pada spesimen yang telah dibuat yang pada akhirnya akan mendapatkan data-data hasil pengujian. Data yang didapatkan dari hasil pengujian akan dianalisa apakah nilai yang didapatkan memenuhi standar minimum dari Biro Klasifikasi Indonesia.

Setelah didapatkan sifat mekanis material laminasi hybrid selanjutnya akan dilakukan perhitungan ukuran konstruksi sesuai dengan peraturan yang telah ditetapkan oleh Biro Klasifikasi Indonesia. Dan pada akhirnya akan dilakukan 
perhitungan ekonomis laminasi hybrid sebagai material konstruksi Kapal Ikan 20 GT yang akan dibandingkan dengan penguunaan Kayu Jati solid KK II.

Ukuran utama Kapal Ikan 20 GT didapatkan dengan melakukan survey lapangan di Desa Kandangsemangkon Kecamatan Paciran Kabupaten Lamongan. Selain untuk mendapatkan ukuran utama survey dilakukan untuk mendapatkan koordinat gading dari Kapal Ikan 20 GT. Kemudian setelah didapatkan koordinat gading dilakukan proses penggambaran lines plan dengan menggunakan bantuan software AutoCAD dan Maxsurf Modeler.

Untuk mendapatkan sifat mekanis laminasi hybrid dengan variasi arah arah serat dilakukan pengujian tarik dan tekuk terhadap spesimen dengan menggunakan standar ASTMD3500 [6] untuk pengujian tarik dan ASTM D-3043 [7] untuk pengujian tekuk. Setelah dilakukan pengujian terhadap spesimen kemudian akan dilakukan analisa teknis terhadap kekuatan mekanis dari masing-masing variasi laminasi hybrid antara Bambu Ori dengan Kayu Sonokembang. Analisa teknis dilakukan untuk mengetahui apakah sifat mekanis laminasi hybrid ini memenuhi tegangan ijin BKI, yang menjelaskan bahwa tegangan ijin minimum untuk kuat tarik adalah 42,169 MPa dan tegangan ijin minimum untu kuat tekuk adalah 72,098 $\mathrm{MPa}[8]$.

Dalam penentuan ukuran konstruksi dari kapal ikan 20 GT digunakan rules dari BKI tahun 2013 tentang "Rules for Small Vessels up to 24 m”. Ukuran konstruksi dari Kapal Ikan 20 GT ini sangat dipengaruhi dari sifat mekanis material yang digunakan. Selain menghitung ukuran konstruksi kapal ikan berbahan laminasi hybrid, juga diperlukan perhitungan konstruksi kapal ikan berbahan Kayu Jati Solid KK II. Hal ini dilakukan untuk mendapatkan perbandingan volumetrik bahan dasar yang digunakan sebagai pembuatan Kapal Ikan 20 GT.

Perhitungan komponen konstruksi seperti kulit dan geladak terlebih dahulu menghitung ketebalan kulit dan geladak Kapal Ikan 20 GT berbahan Kayu Jati Solid dengan menggunakan angka penunjuk, kemudian untuk menghitung ketebalan kulit dan geladak kapal ikan berbahan laminasi hybrid digunakan formula 2. Dimana nilai dari $\sigma_{\mathrm{Rm}}$ adalah nilai dari kuat tekuk hasil dari pengujian..

$$
\begin{aligned}
& t=0,0452 \cdot f_{k} \cdot b \cdot \sqrt{\frac{P_{d}}{\sigma_{R m}}} \\
& t_{1} \sqrt{\frac{P_{d 1}}{\sigma_{R m 1}}}=t_{2} \sqrt{\frac{P_{d 2}}{\sigma_{R m 2}}}
\end{aligned}
$$

Sedangkan untuk perhitungan ukuran konstruksi lainnya seperti lunas, linggi, galar, wrang dan gading. Langkah perhitungan ukuran konstruksi ini sama seperti dalah perhitungan kulit dan geladak, dimana dicari terlebih dahulu modulus dari masing-masing bagian konstruksi Kapal Ikan 20 GT berbahan Kayu Jati Solid kemudian untuk perhitungan ukuran konstruksi kapal ikan berbahan dasar laminasi hybrid digunakan rumus perbandingan momen, dimana nilai dari $\sigma$ adalah nilai kuat tarik dari masing-masing material dasar.

$$
\begin{aligned}
& M_{1}=M_{2} \\
& \sigma_{1} W_{1}=\sigma_{2} W_{2}
\end{aligned}
$$

Setelah didapatkan ukuran konstruksi dari Kapal Ikan 20 GT dengan material dasar yang berbeda kemudian akan dihitung nilai volumetrik kebutuhan materialnya. Dari total volumetrik ini kemudian akan dihitung berapa biaya yang dibutuhkan untuk pembangunan Kapal Ikan 20 GT dengan material laminasi hybrid dan Kayu Jati Solid.

\section{HASIL DAN PEMBAHASAN}

\section{A. Hasil Pengujian Tarik}

Dari hasil pengujian tarik yang telah dilakukan terhadap 4 variasi susunan arah serat laminasi hybrid kemudian akan di rata-rata nilai elongation dan $F_{u l t}$-nya, seperti terlihat pada Gambar 1.

Berdasarkan Gambar 1 spesimen laminasi hybrid dengan susunan arah serat sejajar memiliki nilai rata-rata elongation dan $F_{\text {ult }}$ tertinggi, yaitu $39,56 \mathrm{~mm}$ untuk nilai elongation ratarata dan $29,44 \mathrm{kN}$ untuk nilai $F_{\text {ult }}$ rata-rata. Sedangkan pada spesimen laminasi hybrid dengan susunan arah serat menyilang memiliki rata-rata terendah pada kedua komponen tersebut, yaitu 21,72 mm untuk nilai elongation rata-rata dan 13,04 kN untuk nilai $F_{\text {ult }}$ rata-rata. Sedangkan pada laminasi hybrid dengan variasi susunan arah serat diagonal memiliki nilai elongation rata-rata sebesar $32,56 \mathrm{~mm}$ dan untuk rata-rata $F_{u l t^{-}}$ nya adalah 19,6 kN. Dan pada laminasi hybrid susunan arah serat diagonal silang memiliki nilai rata-rata elongation dan $F_{\text {ult }}$ masing-masing sebesar 30,54 mm dan $17,72 \mathrm{kN}$.

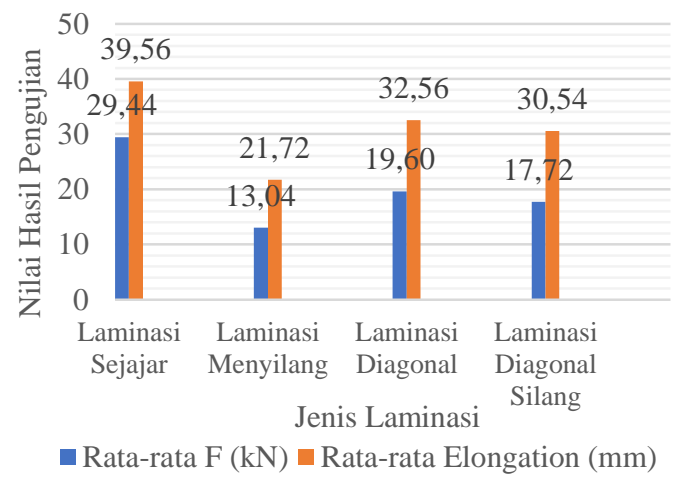

Gambar 1. Grafik hasil uji tarik laminasi hybrid

\section{B. Hasil Pengujian Tekuk}

Dari hasil pengujian tarik yang telah dilakukan terhadap 4 variasi susunan arah serat laminasi hybrid kemudian akan di rata-rata nilai elongation dan $F_{u l t}$-nya, seperti terlihat pada Gambar 2

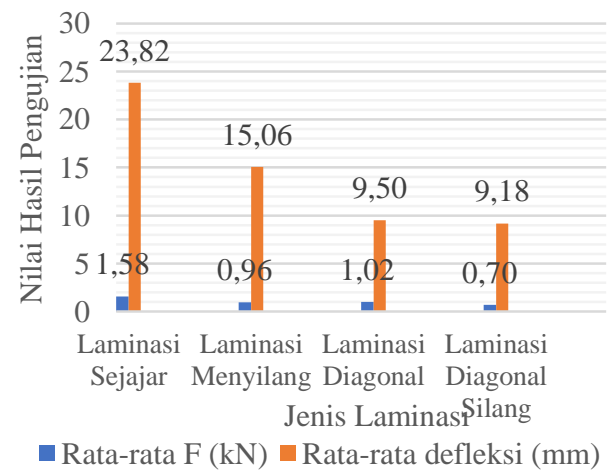

Gambar 2. Hasil pengujian tekuk laminasi hybrid

Berdasarkan Gambar 2 spesimen laminasi hybrid dengan susunan arah serat sejajar memiliki nilai rata-rata defleksi dan 
$F_{\text {ult }}$ tertinggi, yaitu $23,82 \mathrm{~mm}$ untuk nilai defleksi rata-rata dan $1,58 \mathrm{kN}$ untuk nilai $F_{\text {ult }}$ rata-rata. Sedangkan pada spesimen laminasi hybrid dengan susunan arah serat menyilang memiliki rata-rata $15,06 \mathrm{~mm}$ untuk nilai defleksi dan $0.96 \mathrm{kN}$ untuk nilai $F_{u l t}$. Sedangkan pada laminasi hybrid dengan variasi susunan arah serat diagonal memiliki nilai defleksi rata-rata sebesar 9,5 mm dan untuk rata-rata $F_{u l t}$-nya adalah $1,02 \mathrm{kN}$. Dan pada laminasi hybrid susunan arah serat diagonal silang memiliki nilai rata-rata defleksi dan $F_{u l t}$ masing-masing sebesar $9,18 \mathrm{~mm}$, dan $0,7 \mathrm{kN}$.

\section{Data Ukuran Utama}

Survey dilakukan terhadap Kapal Ikan Citra Buana. Didapatkan koordinat-koordinat yang diukur dari setiap gadingnya. Kemudian dari koordinat yang telah didapatkan kemudian akan di redraw dengan cara memasukan koordinat ke dalam AutoCAD yang pada akhirnya akan diperoleh bentuk lines plan dari Kapal Ikan 20 GT ini.

Selain pengukuran langsung koordinat tiap gading, penulis juga melakukan wawancara langsung terhadap pemilik kapal. Dan dari hasil wawancara dengan narasumber didapatkan data ukuran utama Kapal Ikan 20 GT sebagai berikut :

$\begin{array}{ll}\text { Panjang Kapal (Loa) } & : 12 \text { meter } \\ \text { Panjang Garis Air (Lwl) } & : 11,4 \text { meter } \\ \text { Lebar Kapal (B) } & : 4 \text { meter } \\ \text { Tinggi Kapal (H) } & : 4,435 \text { meter } \\ \text { Sarat (T) } & : 1,585 \text { meter } \\ \text { Kecepatan } & : 7 \text { knot }\end{array}$

\section{Nilai Mekanis Pengujian Tarik}

Dapat dilihat pada Gambar 3, Gambar 4 dan Gambar 5 hasil perhitungan nilai Stress, MoE dan Strain dari hasil pengujian tarik yang telah dilakukan terhadap spesimen laminasi hybrid antara Bambu Ori dengan Kayu Sonokembang. Didapatkan rata-rata nilai stress pada laminasi hybrid dengan susunan arah serat sejajar yaitu sebesar 114,636 Mpa, laminasi hybrid dengan susunan arah serat menyilang sebesar 53,814 Mpa, rata-rata nilai stress laminasi hybrid dengan susunan arah serat diagonal sebesar 80,074 Mpa dan rata-rata nilai stress pada laminasi hybrid dengan susunan arah serat diagonal silang sebesar 72,948 Mpa. Sedangkan untuk rata-rata nilai MoE pada laminasi hybrid susunan arah serat sejajar sebesar 11,904 Gpa, rata-rata nilai MoE laminasi hybrid susunan arah serat menyilang sebesar 10,405 Gpa, rata-rata nilai MoE laminasi hybrid susunan arah serat diagonal sebesar 10,448 Gpa dan rata-rata nilai MoE laminasi hybrid susunan arah serat diagonal silang sebesar 9,834 Gpa.

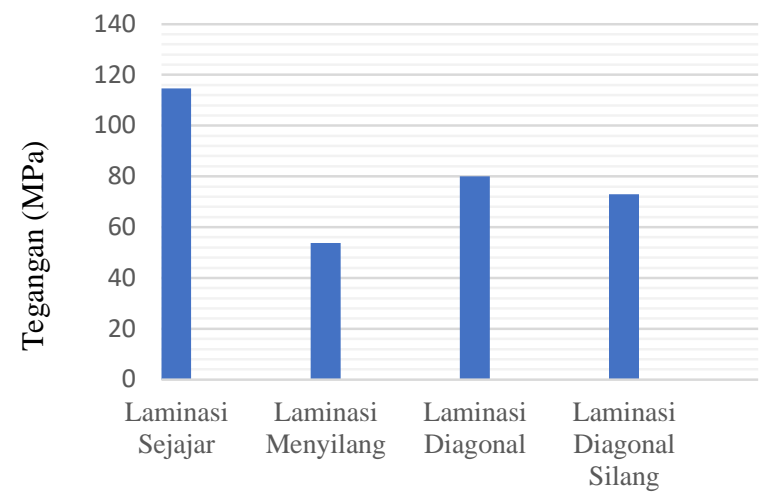

Gambar 3. Grafik rata-rata tegangan hasil uji tarik material laminasi hybrid

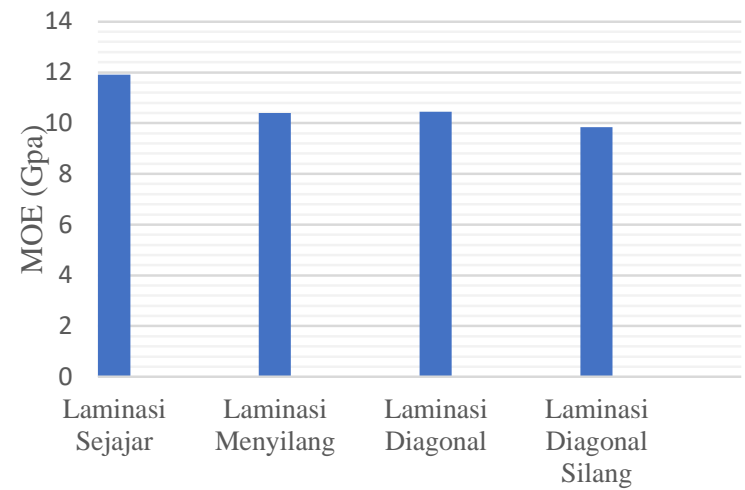

Gambar 4. Grafik rata-rata modulus elastisitas hasil uji tarik laminasi hybrid

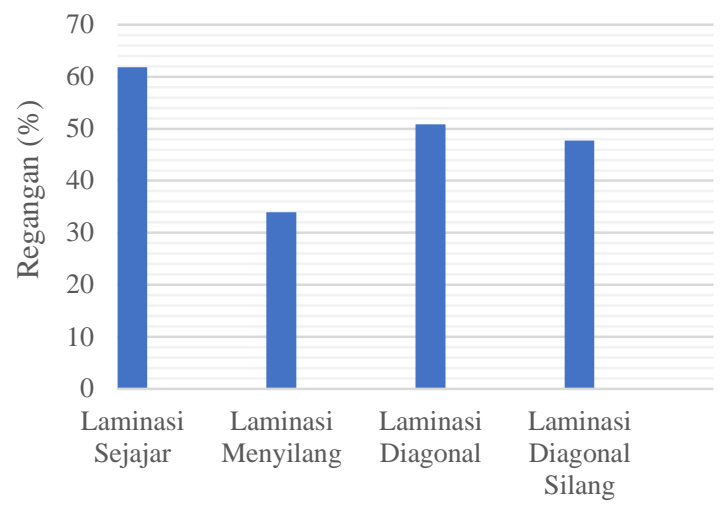

Gambar 5. Grafik rata-rata regangan hasil uji tarik laminasi hybrid

\section{E. Nilai Mekanis Pengujian Tekuk}

Hasil perhitungan nilai defleksi, bending strength dan MOE dari pengujian tekuk spesimen laminasi hybrid antara Bambu Ori dengan Kayu Sonokembang yang telah dilakukan dapat dilihat pada Gambar 6, Gambar 7 dan Gambar 8. Rata-rata nilai defleksi yang terjadi pada spesimen uji tekuk susunan arah serat sejajar adalah sebesar 23,820 mm, rata-rata nilai MoR sebesar 111,606 MPa dan rata-rata nilai MoE sebesar 8,908 GPa. Ratarata nilai defleksi pada spesimen uji tekuk laminasi hybrid dengan susunan arah serat menyilang adalah sebesar 15,060 $\mathrm{mm}$ dan rata-rata nilai MoR-nya sebesar $68,403 \mathrm{MPa}$ dan ratarata nilai MoE sebesar 9,380 GPa. Pada laminasi hybrid dengan susunan arah serat diagonal memiliki rata-rata nilai defleksi sebesar 9,5 mm dengan rata-rata nilai MoR sebesar 70,415 MPa 
dan rata-rata nilai $\mathrm{MoE}$ sebesar 15,281 . Sedangkan rata-rata nilai defleksi dan MoR pada laminasi hybrid dengan susunan arah serat diagonal silang adalah 9,180 $\mathrm{mm}$ dan $39,635 \mathrm{MPa}$, sedangkan rata-rata nilai MOE pada laminasi hybrid arah serat diagonal silang adalah sebesar 7,937 GPa.

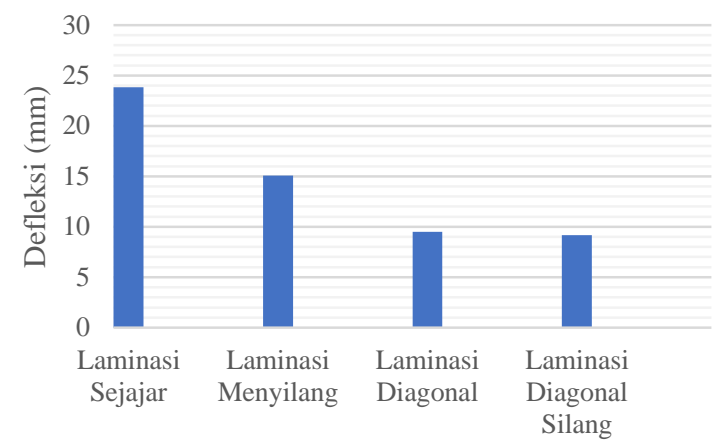

Gambar 6. Rata-rata defleksi hasil uji tekuk laminasi hybrid

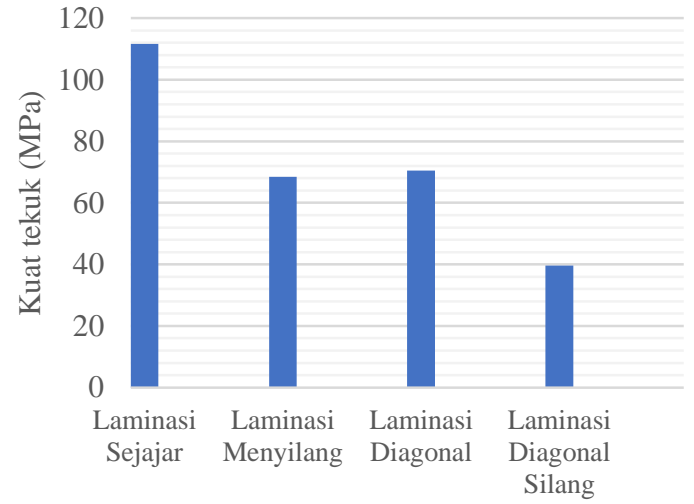

Gambar 7. Grafik rata-rata kuat tekuk laminasi hybrid

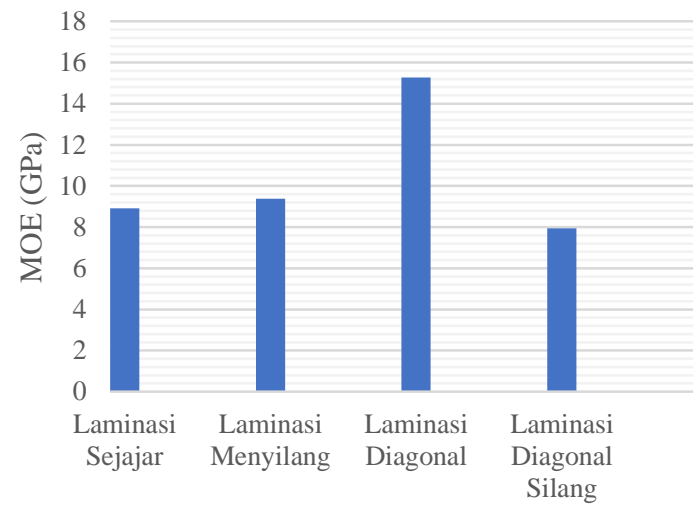

Gambar 8. Grafik rata-rata modulus elastisitas hasil uji tekuk laminasi hybrid

\section{F. Perhitungan Ukuran Konstruksi}

Tabel 1.

Rekapitulasi ukuran konstruksi Kapal Ikan 20 GT

\begin{tabular}{lrrrr}
\hline \hline \multirow{2}{*}{$\begin{array}{c}\text { Bagian } \\
\text { Konstruksi }\end{array}$} & \multicolumn{2}{c}{ Laminasi Hybrid } & \multicolumn{2}{c}{ Kayu Solid } \\
\cline { 2 - 5 } & face & $\begin{array}{c}\text { web } \\
(\mathrm{mm})\end{array}$ & $\begin{array}{c}\text { face } \\
(\mathrm{mm})\end{array}$ & $\begin{array}{c}\text { web } \\
(\mathrm{mm})\end{array}$ \\
\hline Lunas & 200 & 285 & 220 & 340 \\
Linggi & 180 & 220 & 190 & 280 \\
Gading & 110 & 170 & 125 & 194 \\
Galar Balok & 50 & 150 & 61 & 295
\end{tabular}

\begin{tabular}{lrrrr} 
Galar & 50 & 135 & 96 & $\begin{array}{r}96 \\
\text { Galar Kim }\end{array}$ \\
\hline \multicolumn{1}{c}{$\begin{array}{r}\text { Bagian } \\
\text { Konstruksi }\end{array}$} & $\begin{array}{r}\text { tebal } \\
(\mathrm{mm})\end{array}$ & $\begin{array}{r}\text { tinggi } \\
(\mathrm{mm})\end{array}$ & $\begin{array}{r}\text { tebal } \\
(\mathrm{mm})\end{array}$ & $\begin{array}{r}\text { tinggi } \\
(\mathrm{mm})\end{array}$ \\
\hline Kulit & 36 & - & 42 & - \\
Geladak & 35 & - & 51 & - \\
$\begin{array}{l}\text { Dinding } \\
\text { bangunan atas }\end{array}$ & 36 & 2500 & 51 & 2500 \\
$\begin{array}{l}\text { Geladak } \\
\text { bangunan atas }\end{array}$ & 30 & - & 45 & - \\
Wrang (t x h) & 69 & 285 & 85 & 285 \\
\hline \hline
\end{tabular}

Seperti yang dapat dilihat pada Tabel 1, bahwa ukuran konstruksi Kapal Ikan 20 GT dengan material dasar Kayu Jati solid lebih tebal daripada menggunakan material dasar laminasi hybrid antara Bambu Ori dengan Kayu Sonokembang. Didapatkan total volumetrik dari konstruksi Kapal Ikan 20 GT berbahan dasar Kayu Solid adalah 13,75 $\mathrm{m}^{3}$ dan 9,32 $\mathrm{m}^{3}$ untuk kapal ikan berbahan dasar laminasi hybrid. Sehingga didapatkan selisih volumenya sebesar $4,43 \mathrm{~m}^{3}$ atau $32,2 \%$.

\section{G. Analisa Ekonomis}

Biaya pembangunan Kapal Ikan 20 GT berbahan Kayu Jati solid akan dibandingkan dengan laminasi hybrid antara Bambu Ori dan Kayu Sonokembang yang dapat dilihat pada Tabel 2. Berdasarkan Tabel 2 didapatkan biaya pembangunan Kapal Ikan 20 GT berbahan dasar laminasi hybrid dibutuhkan biaya sebesar Rp. 460.881.589,-- sedangkan biaya yang dibutuhkan untuk pembangunan kapal ikan dengan bahan dasar kayu solid sebesar Rp. 776.676.472,-. Dari sini dapat disimpulkan bahwa pembangunan Kapal Ikan 20 GT berbahan dasar laminasi hybrid antara Bambu Ori dan Kayu Sonokembang lebih murah Rp. 315.794.883,- dari kapal ikan berbahan dasar kayu solid, yang artinya penggunaan material laminasi hybrid sebagai material utama pembuatan Kapal Ikan 20 GT lebih ekonomis $40,66 \%$.

Tabel 2.

Biaya pembangunan Kapal Ikan 20 GT

\begin{tabular}{|c|c|c|c|}
\hline \multirow[b]{2}{*}{ Item } & \multicolumn{2}{|c|}{ Biaya (Juta Rupiah) } & \multirow{2}{*}{$\begin{array}{c}\text { Selisih } \\
\text { (Juta Rp) }\end{array}$} \\
\hline & $\begin{array}{c}\text { Laminasi } \\
\text { Hybrid }\end{array}$ & $\begin{array}{l}\text { Kayu } \\
\text { Solid }\end{array}$ & \\
\hline Biaya Material & 306,5 & 550,1 & 243,6 \\
\hline Biaya Tenaga Kerja & 86,2 & 127,2 & 41 \\
\hline Biaya Variabel & 65,4 & 96,5 & 31,1 \\
\hline Biaya Pokok & 2,7 & 2,7 & 0 \\
\hline Total (Rp) & 460,8 & 776,5 & 315,7 \\
\hline
\end{tabular}

\section{KESIMPULAN DAN SARAN}

Dari analisis, perhitungan teknis dan ekonomis mengenai pembangunan kapal ikan menggunakan laminasi hybrid antara Bambu Ori dengan Kayu Sonokembang dengan variasi arah serat, dapat ditarik kesimpulan sebagai berikut:

1. Laminasi hybrid dengan variasi arah serat sejajar mempunyai nilai kuat tarik dan kuat tekuk 114,636 MPa 111,606 $\mathrm{MPa}$, sehingga laminasi ini memenuhi persyaratan minimum dari BKI.

2. Volumetrik konstruksi Kapal Ikan 20 GT menggunakan laminasi hybrid sebesar 9,32 $\mathrm{m}^{3}$, sehingga dibutuhkan total biaya pembangunan sebesar Rp. 460.881.589,sedangkan volumetrik ukuran konstruksi kapal ikan 
menggunakan Kayu Jati Solid sebesar 13,75 $\mathrm{m}^{3}$ yang membutuhkan biaya sebesar Rp. 776.676.472,-, dengan selisih volumetriknya sebesar $4,43 \mathrm{~m}^{3}$ atau sebesar $32,2 \%$ serta selisih biayanya sebesar Rp. 315.794.88.,- atau sebesar $40,66 \%$.

Saran-saran yang dapat diberikan untuk pengembangan studi ini adalah sebagai berikut:

1. Dilakukan laminasi hybrid dengan material yang sama dengan sudut kemiringan yang berbeda-beda pada susunan arah serat diagonal.

2. Pada penelitian selanjutnya disarankan menggunakan jenis bambu dan kayu yang berbeda.

\section{UCAPAN TERIMA KASIH}

Penulis mengucapkan terima kasih, yang pertama kepada Bapak Dr. Ir. Heri Supomo, M.Sc. selaku dosen pembimbing. Kedua kepada Ayah dan Ibu yang telah memberikan dukungan doa dan biaya demi terselesaikannya penelitian ini. Ketiga kepada teman-teman dan pihak-pihak yang tidak dapat Penulis sebutkan satu per satu.

\section{DAFTAR PUSTAKA}

[1] F. W. Indonesia, Potret Keadaan Hutan Indonesia 2009-2013. Bogor: FWI, 2014.

[2] B. K. Indonesia, Rules for Small Vessels up to $24 \mathrm{~m}$ Vol VII. Jakarta: BKI, 2013.

[3] D. R. Indonesia, "HJD Kayu Sonokembang," dutarimba, 2016. [Online]. Available: http://dutarimba.com/2012/06/hjd-kayu-sonokembang.html.

[4] B. Indonesia, "bamboeindonesia.wordpress.com," 2017.

[5] H. Supomo, "Studi Penggunaan Bambu Sebagai Material Alternatif untuk Bahan Pembuatan Kapal Ikan dengan Metode Cold Press Planking System," ITS, 2016.

[6] ASTM, Standard Test Method for Structural Panel in Tensile D3500. New York: ASTM, 2004.

[7] A. D-3043, Standard Test Method for Structural Panel in Flexure and Tension. New York: American Society for Testing and Materials (ASTM), 2004.

[8] B. K. Indonesia, Peraturan Kapal Kayu Vol VI. Jakarta: BKI, 1996. 